\title{
The long-term outcome of hip replacement in adults with juvenile idiopathic arthritis
}

\author{
THE INFLUENCE OF STEROIDS AND METHOTREXATE
}
A. Malviya,
L. C. Walker,
P. Avery,
S. Osborne,
D. J. Weir,
H. E. Foster,
D. J. Deehan

From the

Musculoskeletal

Unit, Freeman

Hospital, Newcastleupon-Tyne, United

Kingdom

\footnotetext{
A. Malviya, FRCS(Tr\&Orth), Specialist Registrar

S. Osborne, RGN, ONC, BSc Hons, Arthroplasty Nurse Practitioner

D. J. Weir, FRCS(Tr\&Orth),

Consultant Orthopaedic

Surgeon

D. J. Deehan, MD, MSc

FRCS(Tr\&Orth), Professor

Consultant Orthopaedic

Surgeon

Musculoskeletal Unit

Newcastle Hospitals NHS Trust,

Freeman Hospital, High

Heaton, Newcastle-upon-Tyne

NE7 7DN, UK.
}

L. C. Walker Medical Student P. Avery, PhD, Senior

Lecturer, School of

Mathematics and Statistics

H. E. Foster, MD, FRCPCH

FRCP, DCH, Cert Med Ed,

Professor of Paediatric

Rheumatology

University of Newcastle,

Claremont Road, Newcastle-

upon-Tyne NE1 7RU, UK.

Correspondence should be sent to Mr A. Malviya; e-mail: amalviya@nhs.net

(C)2011 British Editorial Society of Bone and Joint Surgery doi:10.1302/0301-620X.93B4 $26078 \$ 2.00$

$J$ Bone Joint Surg $[\mathrm{Br}]$

2011;93-B:443-8.
Received 12 October 201

Received 12 October 2010

November 2010

Juvenile idiopathic arthritis (JIA) is a chronic disease of childhood; it causes joint damage which may require surgical intervention, often in the young adult. The aim of this study was to describe the long-term outcome and survival of hip replacement in a group of adult patients with JIA and to determine predictors of survival for the prosthesis. In this retrospective comparative study patients were identified from the database of a regional specialist adult JIA clinic. This documented a series of 47 hip replacements performed in 25 adult patients with JIA. Surgery was performed at a mean age of 27 years (11 to 47), with a mean follow-up of 19 years (2 to 36 ). The mean Western Ontario and McMaster Universities osteoarthritis index questionnaire (WOMAC) score at the last follow-up was 53 (19 to 96) and the mean Health Assessment Questionnaire score was 2.25 (0 to 3). The mean pain component of the WOMAC score (60 (20 to 100)) was significantly higher than the mean functional component score (46 (0 to 97)) ( $p=0.02)$. Kaplan-Meier survival analysis revealed a survival probability of $46.6 \%$ (95\% confidence interval 37.5 to 55.7 ) at 19 years, with a trend towards enhanced survival with the use of a cemented acetabular component and a cementless femoral component. This was not, however, statistically significant (acetabular component, $\mathrm{p}=\mathbf{0 . 7 6}$, femoral component, $\mathrm{p}=\mathbf{0 . 4 5}$ ). Cox's proportional hazards regression analysis showed an implant survival rate of $54.9 \%$ at 19 years at the mean of covariates.

Survival of the prosthesis was significantly poorer $(p=0.001)$ in patients who had been taking long-term corticosteroids and significantly better $(p=0.02)$ in patients on methotrexate.

Juvenile idiopathic arthritis (JIA) is a common rheumatic disease of childhood and over onethird of affected patients enter adulthood with ongoing active arthritis or sequelae from previous inflammation. ${ }^{1}$ The last decade has witnessed considerable changes in its management as a result of studies that report poor long-term physical, functional and psychosocial outcomes in adults with JIA. ${ }^{2-4}$ There has also been a tendency towards more aggressive, focused medical management, with increasingly effective treatments and greater scrutiny of the existing surgical options. ${ }^{5,6}$ We have reported some evidence that introducing methotrexate early may delay the need for joint surgery, ${ }^{7}$ and it is possible that such changes will lessen the need for orthopaedic intervention.

The hip joint may be involved in up to $60 \%$ of children with $\mathrm{JIA}^{8}$ and is a predictor of poor outcome in terms of long-term joint damage. ${ }^{9}$ Total hip replacement (THR) remains the benchmark treatment for end-stage disease in this difficult group of patients, ${ }^{4,10}$ and affords good relief of pain and an improved quality of life for most, ${ }^{11}$ at least in the short term.

In the past, steroids have been the mainstay of treatment. However, these may lead to reduced bone density, poor bone growth and potential debonding of the prosthesis, ${ }^{12,13}$ and implant survival may be limited because of their long-term use. ${ }^{14}$ The effect of methotrexate on implant survival is unclear.

Different types of implant have been used for hip replacement, but there is no consensus which is best. There are no statistically significant comparisons between cemented and uncemented prostheses in the literature. ${ }^{15}$

In 1995 a clinic for adults with JIA was set up in our hospital to provide a regional service. Its purpose was to provide continuity of care for young adult patients with JIA who had been transferred from the children's arthritis service of the same NHS Trust, as well as for all adult patients with JIA, many of whom were previously under the care of adult rheumatologists in the same unit. Patients were managed by one 
Table I. Characteristics of patients at the time of orthopaedic assessment

\begin{tabular}{lc}
\hline Number of hips & 47 (25 patients) \\
Gender & \\
$\quad$ Male:female (\%) & $13: 34$ (30:70) \\
Mean age at onset in years (range) & 7.8 (2 to 14) \\
Mean age at surgery in years (range) & 27.4 (11 to 47$)$ \\
Mean disease duration prior to primary joint surgery (yrs) (range) & 37.5 (4 to 41$)$ \\
Mean age at follow-up in years (range) & 45.6 (26 to 78$)$ \\
Mean follow-up in years (range) & 18.7 (2 to 34$)$ \\
Mean body mass index (range) & 24 (16.2 to 39) \\
Medication history (\%) & \\
$\quad$ Exposure to systemic corticosteroids & 15 (60) \\
Prior to primary joint surgery & 10 (40) \\
Use of methotrexate & 11 (44) \\
Subtype of JIA* & \\
Polyarticular & \\
RF ${ }^{\dagger}$ positive & \\
RF negative & 7 \\
Systemic & 7 \\
Oligo-articular & 3 \\
\hline JIA, juvenile idiopathic arthritis &
\end{tabular}

consultant (HEF) and all patients classified using the International League of Associations for Rheumatology criteria for JIA, which has replaced previous terminologies, including juvenile rheumatoid and juvenile chronic arthritis. ${ }^{16}$

We were therefore uniquely placed to review a group of adult JIA patients in order to answer the following questions: What are the long-term functional status and hip scores of patients with JIA who required hip replacement? What is the long-term survival of hip replacement in this group of patients? Is the survival of the prosthesis dependent on the type of fixation (cemented $v s$ cementless)? and Do steroids and methotrexate affect long-term survival?

\section{Patients and Methods}

From the department database of 144 adult patients with JIA we identified a cohort of 25 (47 hips) who had undergone hip replacement between 1976 and 2007. All of these were included in the study. Patient details, including body mass index (BMI) at the most recent review, JIA subtype, disease duration, age of onset, age at THR, orthopaedic interventions and exposure to anti-rheumatic drugs and corticosteroids were collated (Table I). Surgical and preoperative data were collected from the case notes. Patients were reviewed in an independent clinic by an arthroplasty nurse specialist to assess their functional status, Health Assessment Questionnaire (HAQ) scores $^{17}$ and Western Ontario and McMaster Universities osteoarthritis index (WOMAC) hip score. ${ }^{18,19}$ The Stanford HAQ 20-Item Disability Scale Index is a self-reported disability measure that has been validated and widely used for clinical trials in adult rheumatoid arthritis and other rheumatic diseases. ${ }^{20,21}$ The construct validity, predictive validity and sensitivity to change of the HAQ-20 have also been established in numerous observational studies and clinical trials, albeit not for JIA. The HAQ (score 0 to 3 , with 3 being the worst functional ability) is an assessment of functional disability and is predictive of long-term patient outcome and survival of the joint replacement in patients with adult-onset rheumatoid arthritis, with some evidence of its predictive value in a cohort of adults with JIA requiring knee replacement. ${ }^{22}$ The WOMAC score is a self-administered questionnaire covering three main domains of pain, stiffness and function, and has been validated for assessing patients with osteoarthritis of the hip and arthritis of the knee. ${ }^{19}$ Each domain is scored out of 100 .

Statistical analysis. Clinical (pain and stiffness components of WOMAC score) and functional (WOMAC functional component; HAQ score for generic health) outcome was assessed. SPSS v 15 Statistical package (SPSS Inc., Chicago, Illinois) was used for the analyses. Kaplan-Meier survival curves were constructed with $95 \%$ confidence intervals (CI) to establish the survival of the THRs. The relationship between the WOMAC and HAQ scores was examined with Pearson's correlation coefficient. A multivariate Cox's proportional hazard regression analysis was carried out using implant survival as the response variable to exclude the effect of confounding variables, which could adversely affect the interpretation of the survival analyses. These include age at onset of disease, age at the time of THR, disease subtype, type of implant, gender, and use of steroids and/or methotrexate as possible covariates. Only variables with a p-value $<0.01$ were included in the analyses. Con- 
Table II. Summary of outcome measures

\begin{tabular}{lc}
\hline & Mean score (range) \\
\hline HAQ $^{*}$ & 2 (0 to 3$)$ \\
WOMAC $^{\dagger}$ & $53(19$ to 96$)$ \\
Total & $60(20$ to 100$)$ \\
Pain & $46(0$ to 97$)$ \\
Function & $56(25$ to 75$)$ \\
Stiffness & \\
* HAQ, health assessment questionnaire \\
† WOMAC, Western Ontario and McMaster \\
Universities osteoarthritis index
\end{tabular}

cerns have recently been raised that clinical studies assessing orthopaedic interventions often include data from two limbs or multiple joints from one patient. This may contribute to false precision and possible bias in estimates of treatment effect. ${ }^{23,24}$ Owing to statistical advice we used a stringent $p$-value to counter the effect of bilaterality on an observation. Moreover, we used absolute endpoints such as revision instead of subjective outcome measures, which may cause bias because of two observations on the same patients. The study was registered with the hospital trust audit department and exempted from ethical approval. Statistical significance was set at a p-value $<0.05$.

\section{Results}

The mean follow-up was 18.7 years ( 2 to 34 ). The distribution of the HAQ and WOMAC scores at the time of final review is shown in Table II. High negative correlation (Pearson's coefficient $-0.69 ; \mathrm{p}<0.001$ ) was noted between the HAQ score (dependent variable) and the mean WOMAC scores (independent variable). The pain component of the WOMAC score was significantly better than the functional component $(t$-test, $\mathrm{p}=0.02)$.

Long-term survival. A total of 19 hips $(40.4 \%)$ were revised at a mean of 11 years ( 3 to 21). Of these, eight required further revision at a mean of eight years (1 to 16). The reasons for the first revision are detailed in Table III. Three hips $(6.4 \%)$ had to be revised for recurrent dislocation three to six years after the primary surgery. Two of these developed uncontrolled infection bilaterally after revision surgery. Both required an excision arthroplasty, one nine years after the primary procedure and one after 20 years. Both had been taking long-term oral steroids. One patient with severe systemic JIA from the age of two, complicated by severe growth retardation, amyloidosis and osteoporosis, experienced a peri-prosthetic fracture of the femur 16 years after revision requiring further revision of the femoral component. The Kaplan-Meier survival curve for the whole group is shown in Figure 1 . A survival probability of $46.6 \%$ (95\% confidence interval (CI) 37.5 to 55.7 ) was seen at 19 years, with revision for any cause as the endpoint, and of $58.5 \%$ (95\% CI 48.3 to 68.7) with revision for aseptic loosening as the endpoint. With revision for any cause as the endpoint, the 19-year survival for the acetabular component was $55.3 \%$ (95\% CI
Table III. Indication for first revision

\begin{tabular}{ll}
\hline Cause & Number of hips (\%) \\
\hline Recurrent dislocation & $3(6.4)$ \\
Aseptic loosening & \\
$\quad$ Both & $6(12.8)$ \\
Acetabular component & $8(17.0)$ \\
Femoral component & $2(4.3)$ \\
Peri-prosthetic fracture & 0 \\
Infection & 0 \\
\hline
\end{tabular}

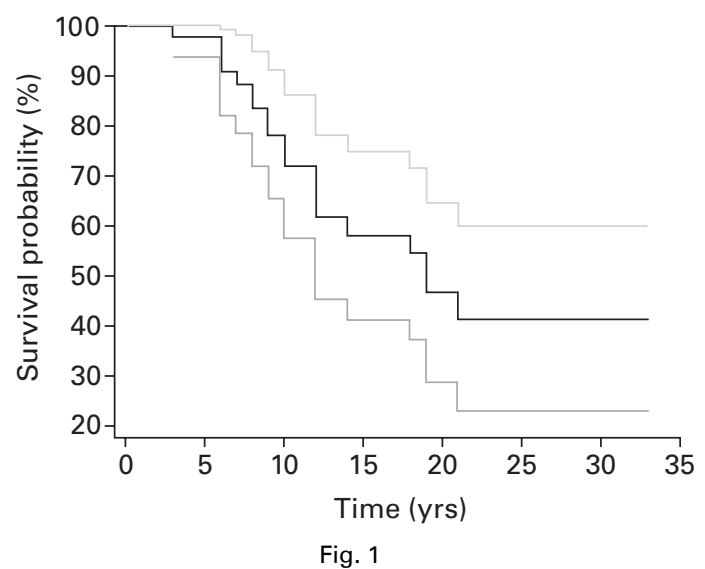

Kaplan-Meier survival curve for the whole group, with revision for any reason as endpoint.

46.4 to 64.2$)$, compared with $79.1 \%$ (95\% CI 71.8 to 86.4 ) for the femoral component $(\mathrm{p}=0.009)$. With revision for aseptic loosening as the endpoint, the 19-year survival for the acetablar component was $64.5 \%$ (95\% CI 55.1 to 73.9 ), compared with $80.1 \%$ (95\% CI 72.5 to 87.7 ) for the femoral component $(\mathrm{p}=0.007)$.

Type of implant and survival. Cemented implants were used in $18(38.3 \%)$ of the THRs (Table IV). There was no significant difference between the survival of cemented and cementless components (mean survival: 13.8 years (2 to 32 ) for cemented versus 14.5 years ( 3 to 33 ) for cementless (chisquared test, $p=0.4)$ ). There was also no significant (chisquared test, $\mathrm{p}=0.73$ ) difference in survival between the various subgroups (cemented, cementless, hybrid and resurfacing). The 19-year survival for a cemented component was $53.6 \%$ (95\% CI 37.8 to 69.4$)$, compared to $47.6 \%$ (95\% CI 36.9 to 58.3 ) for a cementless component. Acetabular component: cemented versus cementless. The acetabular component was revised in 17 hips $(36 \%)$ in 12 patients (Fig. 2), these compromised six of 18 (33.3\%) cemented components and 11 of $29(38 \%)$ cementless components. The survival of cemented acetabular components at 12 and 19 years $(82.5 \%$ (95\% CI 71 to 94$)$ and $61.9 \%$ (95\% CI 46.6 to 77.2 ), respectively) appeared better than that of the cementless acetabular components $164.4 \%$ 
Table IV. Type of implant

\begin{tabular}{llllll}
\hline & & & \multicolumn{2}{l}{ Mean prosthesis survival (yrs) } \\
\cline { 5 - 6 } Type & Number (\%) & Mean follow-up (yrs) & Total & Acetabular component & Femoral component \\
\hline Cemented & $18(38.3)$ & $18.4(1$ to 34$)$ & $13.8(2$ to 32$)$ & $14.8(2$ to 32$)$ & $15.3(2$ to 32$)$ \\
Cementless & $24(51.0)$ & $21.3(10$ to 33$)$ & $14.5(3$ to 33$)$ & $14.5(3$ to 33$)$ & $17.6(9$ to 33$)$ \\
Hybrid & $3(6.4)$ & $9(8$ to 10$)$ & $9(8$ to 10$)$ & $9(8$ to 10$)$ & $9(8$ to 10$)$ \\
Resurfacing & $2(4.3)$ & $4(3$ to 5$)$ & $4(3$ to 5$)$ & $4(3$ to 5$)$ & $4(3$ to 5$)$
\end{tabular}

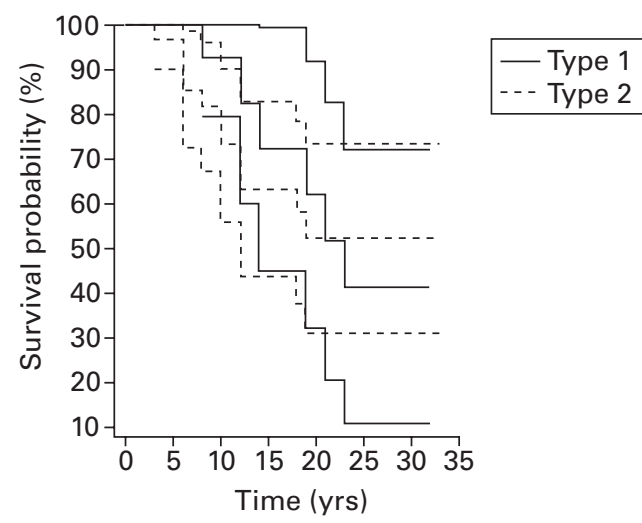

Fig. 2

Kaplan-Meier survival curve for the acetabular component, with revision for any reason as endpoint.

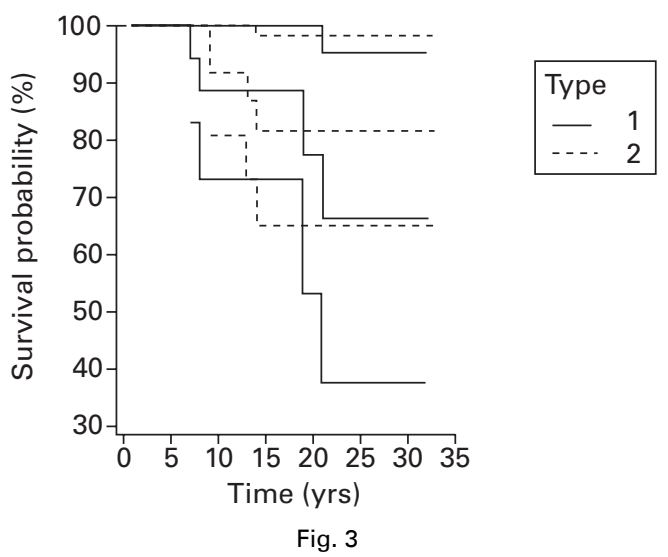

Kaplan-Meier survival curve for the femoral component with revision for any reason as endpoint.

(95\% CI 54.5 to 74.3$)$ and $52.3 \%$ (95\% CI 41 to 63.2$)$, respectively), but this difference was not significant (chisquared test, $\mathrm{p}=0.76$ ).

Femoral component: cemented versus cementless. The femoral component was revised in eight hips (17\%) (Fig. 3). They comprised four of 21 (19\%) cemented components and four of $26(15.4 \%)$ cementless components. We noted that the survival of the cementless components appeared better, with $87 \%$ (95\% CI 80 to 94 ) surviving up to 13 years, compared to an $88 \%$ (95\% CI 80 to 96$)$ survival at eight

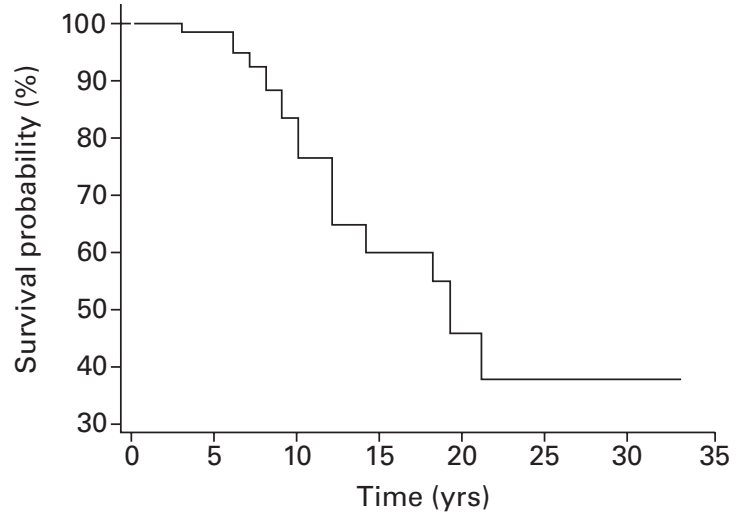

Fig. 4

Cox's proportional hazards regression analysis for the whole group with revision for any reason as endpoint.

years for the cemented components. Again, this difference was not statistically significant (chi-squared test, $\mathrm{p}=0.45$ ). Predictors of survival. Cox's proportional hazards regression analysis (Fig. 4) showed an estimated 19-year survival of $54.9 \%$ (95\% CI 48.9 to 60.9 ) at the mean of covariates after adjusting for the effects of confounding variables such as age of disease onset, age at surgery, gender, disease type, type of implant, use of corticosteroids and methotrexate. For the overall times, taking steroids (Cox's regression, $\mathrm{p}=0.001$ ), gender (Cox's regression, $\mathrm{p}=0.01$ ) and methotrexate (Cox's regression, $\mathrm{p}=0.02$ ) were significant factors. Taking steroids, being female and not taking methotrexate resulted in reduced survival times. However, considered individually, none of the log-rank tests are significant. Only steroid use was significant for acetabular component survival (Cox's, $\mathrm{p}<0.001$ and logrank test, $\mathrm{p}=0.004)$. For femoral component survival, only disease duration was significant (Cox's, $p=0.028$ ). Longer disease durations resulted in shorter implant survival times.

The 19-year survival was higher for those who had not been exposed to corticosteroids $(65 \%$ vs $28.8 \%$, chi-squared test, $\mathrm{p}=0.04$ ) than for those who had (Figs 5 and 6).

\section{Discussion}

Most previous studies pre-date the era in which diseasemodifying antirheumatic drug therapy was started early. Accordingly, these publications do not reflect current clinical practice. The importance of prompt access to 


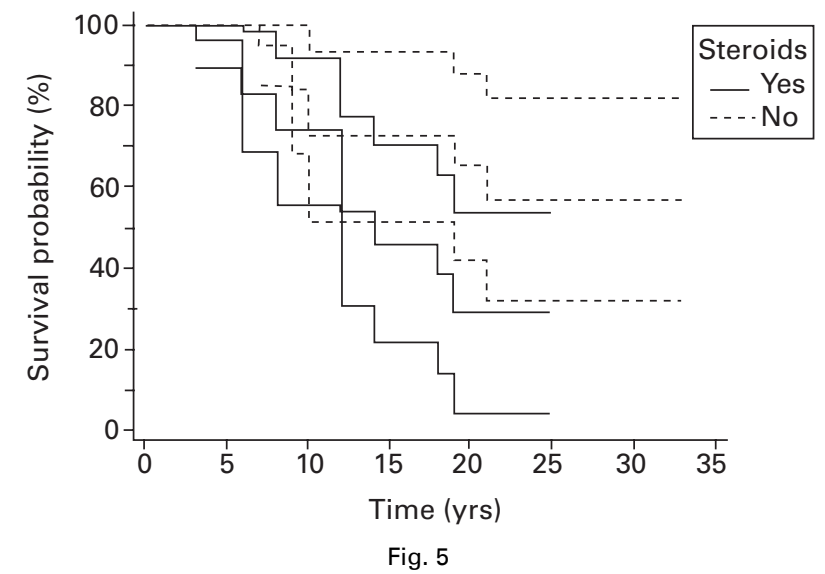

Kaplan-Meier survival analysis looking into the effect of steroids, with revision for any reason as endpoint.

potent, safe pharmacological immunomodulation remains the mainstay of treatment for children with severe subtypes of JIA. ${ }^{5,6}$ However, it remains unclear whether this modern approach will ultimately reduce or delay the need for THR in JIA. Furthermore, it is likely that certain patients with refractory inactive disease may still develop joint damage, deformity, loss of function and pain at a subclinical level and despite improved surveillance require THR in early adulthood. The existing literature supports our findings that THR offers excellent pain relief. In our series we found a substantially higher early failure rate and a greater risk of infection and fracture than in older, non-JIA patients undergoing THR, but there are few or no comparative data for outcomes in an equivalent age group with joint disease from other causes.

With a mean follow-up of 19 years (2 to 36), our study compares favourably to other studies and is one of few with long follow-up. ${ }^{8,10,14,15,25-33} \mathrm{Chmell}_{\text {et }} \mathrm{al}^{8}$ reported an overall failure rate of $44 \%$ for 66 acetabular components and $18 \%$ for the femoral components, with revision or radiological loosening as the endpoint. Lehtimaki et $\mathrm{al}^{14}$ identified improvements in patient mobility and pain relief but did not comment on the types of procedures performed or survival rates. Jinnah et $\mathrm{al}^{34}$ reported a higher failure rate in younger and heavier patients. Wroblewski et $\mathrm{al}^{33}$ reported a survival of $74 \%$ after 25 years in young rheumatoid and JIA patients undergoing Charnley low-friction arthroplasty.

This particular patient group has complications which are accentuated by the systemic nature of JIA and which contribute to the reduced durability of THR. These include osteopenia $(34 \%$ have low total body bone mineral density $^{35}$ ), which may lead to femoral fractures during implant insertion, ${ }^{31}$ contractures, osseous deformities, skeletal remodelling and femoral cortical hypertrophy. ${ }^{8}$

Our study highlights the poor long-term functional results (Table II) associated with surgery in this group of patients. The pain scores were significantly better than the functional

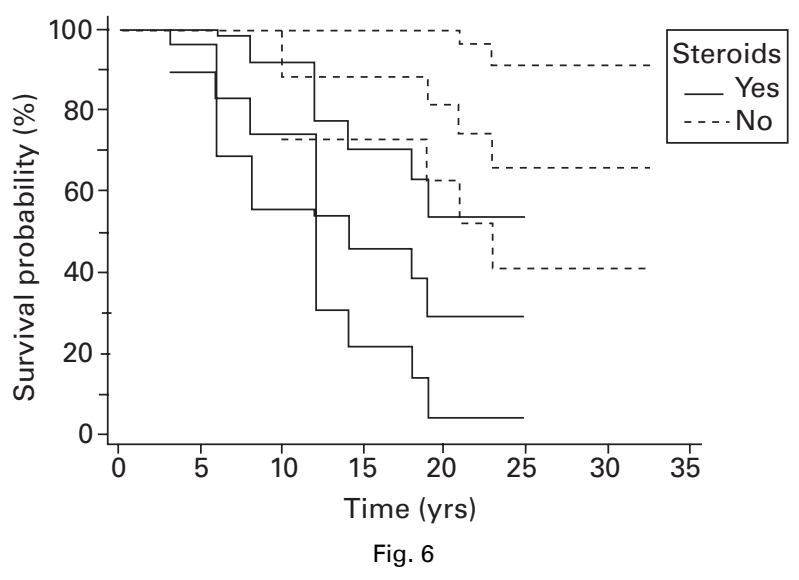

Kaplan-Meier survival analysis of the acetabular component looking into the effect of steroids, with revision for any reason as endpoint.

results $(\mathrm{p}=0.02)$. The high HAQ scores found in our patients reflect functional disability and impact on daily living. A significant $(\mathrm{p}<0.001)$ negative correlation has been found between the HAQ and WOMAC scores, confirming, not surprisingly, that a high grade of disease activity with multisystem involvement may be associated with a poor functional outcome.

A significantly higher proportion of our patients required revision of the acetabular component $(36 \%)$ compared with the femoral component $(17 \%)(p=0.04)$. We found no significant difference in the survival of cemented versus cementless components $(p=0.4)$, although there was a trend towards better survival of the cementless femoral component and the cemented acetabular component. Previous authors have raised the issue of poor porous ingrowth in cementless components, with lack of early predictable fixation because of poor bone stock. ${ }^{31}$ Haber and Goodman ${ }^{31}$ reported excellent pain relief and improvement in function after four years' follow-up, but commented on a rate of discernible ingrowth in only $70 \%$ of cementless femoral components. Odent et $\mathrm{al}^{10}$ also focused solely on cementless hip replacement and showed a survival rate of $100 \%$ for the femoral component and $90.1 \%$ for the acetabular component at 13 years. Excellent results for cementless hips were reported by Maric and Haynes $^{28}$ (nine years' follow-up) and Lachiewicz et $\mathrm{al}^{27}$ (six years' follow-up). However, we have been unable to extract any clear message or information about the influence of the fixation method on complication rates. ${ }^{15}$

The survival analysis supports the view that prolonged corticosteroid use has a negative influence upon the longterm implant survival ( $\mathrm{p}=0.01$ ) (Figs 5 and 6). Potential causes include the deleterious influence on bone ingrowth, ${ }^{12,13}$ and osteopenia resulting in a risk of fracture. These findings concur with those of Lehtimaki et al. ${ }^{14}$ However, we have no data on the exact dose or duration of steroid use. Regression analyses show the significantly beneficial influence of methotrexate on joint survival 
$(p=0.02)$. Methotrexate was first introduced for the management of JIA in Newcastle in 1993, and we have previously reported that starting methotrexate within five years of the onset of disease may delay or reduce the need for joint surgery in young adults. ${ }^{7}$ To the best of our knowledge, this is the first study to show that not taking methotrexate reduces the survival time of joint replacements in this cohort of patients.

This study has several limitations. There is a selection bias towards more severe JIA subtypes, and many patients pre-date the disease-modifying anti-rheumatic drugs era, resulting in some potentially having had unrecorded episodes of active disease and possible exposure to corticosteroids. In addition, the WOMAC and HAQ scores were collected recently, and only limited pre-operative data were available from the case notes. We have taken the most appropriate statistical measures to minimise the effect of bilaterality on the outcome. ${ }^{23,24}$

In summary, we report a high revision rate for hip replacement in an adult cohort of JIA patients with long follow-up. There may be a deleterious effect of corticosteroid use on implant survival and a beneficial effect of methotrexate. Our data support the view that patients who have undergone THR for JIA have better pain scores than functional scores, and there is a trend towards better survival of a cementless femoral component and a cemented acetabular component. Acetabular components required earlier revision than the femoral components, irrespective of mode of fixation.

\section{Supplementary material}

e A table showing the full literature review is available with the electronic version of this article on our website at www.jbjs.org.uk

No benefits in any form have been received or will be received from a commercial party related directly or indirectly to the subject of this article.

\section{References}

1. Ravelli A. Toward an understanding of the long-term outcome of juvenile idiopathic arthritis. Clin Exp Rheumatol 2004;22:271-5

2. Foster HE, Marshall N, Myers A, Dunkley P, Griffiths ID. Outcome in adults with juvenile idiopathic arthritis: a quality of life study. Arthritis Rheum 2003;48:767-75.

3. Packham JC, Hall MA. Long-term follow-up of 246 adults with juvenile idiopathic arthritis: social function, relationships and sexual activity. Rheumatology (Oxford) 2002; $41: 1440-3$.

4. Yun AG, Martin S, Zurakowski D, Scott R. Bipolar hemiarthroplasty in juvenile rheumatoid arthritis: long-term survivorship and outcomes. J Arthroplasty 2002;17:978-86.

5. Beresford MW, Baildam EM. New advances in the management of juvenile idiopathic arthritis-2: the era of biologicals. Arch Dis Child Educ Pract Ed 2009:94:151-6.

6. Beresford MW, Baildam EM. New advances in the management of juvenile idiopathic arthritis-1: non-biological therapy. Arch Dis Child Educ Pract Ed 2009:94:144-50.

7. Malviya A, Johnson-Lynn S, Avery P, Deehan D, Foster H. Juvenile idiopathic arthritis in adulthood and orthopaedic intervention. Clin Rheumato/ 2009;28:1411-17.
8. Chmell MJ, Scott RD, Thomas WH, Sledge CB. Total hip arthroplasty with cement for juvenile rheumatoid arthritis: results at a minimum of ten years in patients less than thirty years old. J Bone Joint Surg [Am] 1997;79-A:44-52.

9. McDonagh JE. Juvenile idiopathic arthritis. In: Banta JV, Scrutton D, eds. Hip disorders in childhood. London: MacKeith, 2003:130-45

10. Odent T, Journeau P, Prieur AM, et al. Cementless hip arthroplasty in juvenile idiopathic arthritis. J Pediatr Orthop 2005;25:465-70.

11. Kitsoulis PB, Siamopoulou A, Beris AE, Xenakis TA. Total hip and knee arthroplasty for juvenile rheumatoid arthritis. Folia Med (Plovdiv) 2006;48:42-9.

12. Shih LY, Shih HN, Chen TH. The effects of sex and estrogen therapy on bone ingrowth into porous coated implant. J Orthop Res 2003;21:1033-40.

13. Stuchin SA, Ruoff M, Matarese W. Cementless total knee arthroplasty in patients with inflammatory arthritis and compromised bone. Clin Orthop 1991:273:42-51.

14. Lehtimaki MY, Lehto MU, Kautiainen H, Savolainen HA, Hamäläinen MM. Survivorship of the Charnley total hip arthroplasty in juvenile chronic arthritis: a follow-up of 186 cases for 22 years. J Bone Joint Surg [Br] 1997;79-B:792-5.

15. Mulhall KJ, Saleh KJ, Thompson CA, Severson EP, Palmer DH. Results of bilateral combined hip and knee arthroplasty in very young patients with juvenile rheumatoid arthritis. Arch Orthop Trauma Surg 2008;128:249-54.

16. Petty RE, Southwood TR, Manners P, International League of Associations for Rheumatology. International league of associations for rheumatology classification of juvenile idiopathic arthritis: second revision, Edmonton, 2001. J Rheumatol 2004;31:390-2.

17. Singh G, Athreya BH, Fries JF, Goldsmith DP. Measurement of health status in children with juvenile rheumatoid arthritis. Arthritis Rheum 1994;37:1761-9.

18. Theiler R, Spielberger J, Bischoff HA, et al. Clinical evaluation of the WOMAC 3.0 $O A$ index in numeric rating scale format using a computerized touch screen version. Osteoarthritis Cartilage 2002;10:479-81.

19. Bellamy N, Buchanan WW, Goldsmith CH, Campbell J, Stitt LW. Validation study of WOMAC: a health status instrument for measuring clinically important patient relevant outcomes to antirheumatic drug therapy in patients with osteoarthritis of the hip or knee. J Rheumato/ 1988;15:1833-40.

20. Fries JF, Spitz P, Kraines RG, Holman HR. Measurement of patient outcome in arthritis. Arthritis Rheum 1980;23:137-45.

21. Fries JF, Spitz PW, Young DY. The dimensions of health outcomes: the health assessment questionnaire, disability and pain scales. J Rheumatol 1982;9:789-93.

22. Malviya A, Foster HE, Avery P, Weir DJ, Deehan DJ. Long term outcome following knee replacement in patients with juvenile idiopathic arthritis. Knee 2009;17:340-4.

23. Bryant D, Havey TC, Roberts R, Guyatt G. How many patients?: how many limbs? analysis of patients or limbs in the orthopaedic literature: a systematic review. J Bone Joint Surg [Am] 2006;88-A:41-5.

24. Park MS, Kim SJ, Chung CY, et al. Statistical consideration for bilateral cases in orthopaedic research. J Bone Joint Surg [Am] 2010;92-A:1732-7.

25. Colville J, Raunio P. Total hip replacement in juvenile rheumatoid arthritis: analysis of 59 hips. Acta Orthop Scand 1979;50:197-203.

26. Ruddlesdin C, Ansell BM, Arden GP, Swann M. Total hip replacement in children with juvenile chronic arthritis. J Bone Joint Surg [Br] 1986;68-B:218-22.

27. Lachiewicz PF, McCaskill B, Inglis A, Ranawat CS, Rosenstein BD. Total hip arthroplasty in juvenile rheumatoid arthritis: two to eleven-year results. J Bone Joint Surg [Am] 1986;68-A:502-8.

28. Maric Z, Haynes RJ. Total hip arthroplasty in juvenile rheumatoid arthritis. Clin Orthop 1993;290:197-9.

29. Witt JD, Swann M, Ansell BM. Total hip replacement for juvenile chronic arthritis. J Bone Joint Surg [Br] 1991;73-B:770-3.

30. Joshi AB, Porter ML, Trail IA, et al. Long-term results of Charnley low-friction arthroplasty in young patients. J Bone Joint Surg [Br] 1993;75-B:616-23.

31. Haber D, Goodman SB. Total hip arthroplasty in juvenile chronic arthritis: a consecutive series. J Arthroplasty 1998;13:259-65.

32. Goodman SB, Oh KJ, Imrie S, Hwang K, Shegog M. Revision total hip arthroplasty in juvenile chronic arthritis: 17 revisions in 11 patients followed for 4-12 years. Acta Orthop 2006;77:242-50.

33. Wroblewski BM, Siney PD, Fleming PA. Charnley low-frictional torque arthroplasty in young rheumatoid and juvenile rheumatoid arthritis: 292 hips followed for an average of 15 years. Acta Orthop 2007;78:206-10.

34. Jinnah RH, Amstutz HC, Tooke SM, Dorey F, Dalseth T. The UCLA Charnley experience: a long-term follow-up study using survival analysis. Clin Orthop 1986;211:164-72.

35. Lien G, Flato B, Haugen M, et al. Frequency of osteopenia in adolescents with early-onset juvenile idiopathic arthritis: a long-term outcome study of one hundred five patients. Arthritis Rheum 2003;48:2214-23. 